DOI: $10.30973 /$ esdi $/ 2018.4 .1 / 3$

ISSN: $2448-4857$

Volumen 4 | Número 1

marzo 2018 | agosto 2018

pp. 20-35

\title{
Protestar en México (primeras reflexiones para un vocabulario teológico-político contra-hegemónico) ${ }^{*}$
}

\author{
Silvana Rabinovich \\ Instituto de Investigaciones Filológicas \\ Universidad Nacional Autónoma de México, México \\ silvanar@unam.mx
}

\begin{abstract}
Resumen
Partiendo de una anécdota sobre los distintos sentidos que en México tiene el verbo "protestar", el presente texto señala su ubicación en la encrucijada de lo teológico y lo político. De allí, se aborda la relación entre teología y política en dos autores divergentes: Carl Schmitt (contrarrevolucionario) y Jacob Taubes (revolucionario). A partir de este último, y tomando en cuenta ciertas protestas en México que se asumen tanto en la dimensión teológica como en la política, se proponen unas primeras reflexiones para pensar un posible vocabulario teológico-político contra-hegemónico.

Palabras clave: protestar, teológico, político, contra-hegemónico, derecho a lo sagrado

Abstract

Based on an anecdote about the different meanings that the verb "protest" has in Mexico, the present text places it at a crossroads between theology and politics. From there, it focuses on the relationship between theology and politics in two divergent authors: Carl Schmitt (counter-revolutionary) and Jacob Taubes (revolutionary). Following the latter, we analyze certain protests in Mexico that are conceived in their theological as well as political dimensions, and suggest preliminary reflections for a potential theological-political counter-hegemonic vocabulary.
\end{abstract}

Keywords: protest, theological, political, counter-hegemonic, right to de sacred

${ }^{*}$ Esta investigación se produce gracias al Proyecto PAPIIT IN 402317 "Heteronomías de la justicia: nomadismo y hospitalidad en el lenguaje" cuya responsable es la autora.

Fecha de recepción: 25 de noviembre de 2017 | Fecha de aceptación: 28 de ene de 2018 
Silvana Rabinovich

i

Protesta usted ejercer su profesión responsable y honestamente, con el respeto, dignidad y ética, que de usted espera la comunidad de la Universidad Nacional Autónoma de México(...)? De no ser así, la Universidad, la sociedad y su propia conciencia serán quienes se lo demanden, me preguntó y advirtió el doctor Enrique Dussel en el año 2000... y yo enmudecí. Repitió la pregunta y el resto del jurado asentía con una sonrisa, como para animarme a hacerlo... En semejante situación, para mí era claro que la performatividad de mi respuesta me abriría las puertas de la enseñanza o me las cerraría definitivamente. Había estado en algunos exámenes profesionales de amigos en otras ocasiones, pero coherente con las sospechas respecto a las formalidades que había aprendido en mi Argentina natal (que andaba a los tumbos entre dictaduras y autoritarismos), nunca había reparado en ese acto final que acontece en México cuando uno asume una responsabilidad ante el Estado, llamado "toma de protesta". Había protestado por muchas injusticias en Argentina, pero no cuando me recibí de licenciada en Filosofía. También protesté en Israel, con enorme indignación, en 1982 contra las masacres de Sabra y Shatila (aunque no 11 años después, cuando terminé la maestría). Pero ¿por qué protestar en mi examen doctoral en la Universidad Nacional Autónoma de México (UnAM), si estaba completamente de acuerdo en ejercer con suma honestidad y máxima responsabilidad el pensamiento, que siempre entendí como un ejercicio parresiástico, tanto en la enseñanza como en cada cosa que escribo? ¿Para qué protestar, si apenas terminaba una etapa más de un aprendizaje interminable? Dije que sí... Mucho más tarde entendí que los académicos (al menos los de universidades nacionales), aunque nos pese reconocerlo, somos funcionarios del Estado. Afortunadamente, en un país que había pasado por una revolución, el texto de la protesta decía que "la sociedad" me demandaría, y en eso estoy de acuerdo: las universidades públicas se deben a la sociedad mexicana (y no al aparato que ocupa el gobierno en turno, que suele darle la espalda).

Entonces, el mismo día de un examen que me habilitaba para ejercer el pensamiento en público, volví a confirmar la vocación filosófica que consiste en escuchar atentamente la genealogía de las palabras y su potencia tantas veces performativa. Efectivamente, "protestar" tiene que ver con jurar, dar testimonio, dar fe, declarar las creencias y también con enfrentar, "oponerse a una cosa por considerarla ilegal 
o ilegítima" (tal como lo define esa gran bibliotecaria de la República española que se quedó en el umbral de la RAE, María Moliner). ${ }^{1}$

Así es como recordé que otro funcionario, el presidente en turno de este país que separa a la Iglesia del Estado (Argentina no lo hacía y los presidentes "juraban" — no "protestaban" - sobre la Biblia: la Iglesia católica no permitiría que "protestaran”...), aquí el ciudadano presidente protesta:

guardar y hacer guardar la Constitución Política de los Estados Unidos Mexicanos y las leyes que de ella emanen, y desempeñar leal y patrióticamente el cargo de Presidente de la República que el pueblo me ha conferido, mirando en todo por el bien y prosperidad de la Unión; y si así no lo hiciere que la Nación me lo demande. (apud Manrique Velasco)

En esta protesta caben los dos sentidos: el primero es el juramento, el segundo es el derecho constitucional de los otros (los que nacieron en esta tierra y los que en ella renacimos en medio de este abanico plurinacional de lenguas y culturas, que va tejiendo una unión sólida - de comunidades, que no de intereses- desde abajo, por ejemplo, en el Congreso Nacional Indígena), a manifestarse en oposición cuando el que juró traiciona su compromiso (esto es, demandarlo... pero, ¿ante quién?).

"Protesta" es una palabra-bisagra entre lo sagrado y lo profano, un acto de habla que atañe al testimonio, al juramento. En ella se dramatiza la tensión entre el mundo trascendente y jerárquico (teológico) y el mundo inmanente que busca equilibrio de fuerzas ( $p$ olítico, en el sentido ilustrado del término). Como acto de habla, la protesta (provenga de la profesión de jerarquía o de la demanda de horizontalidad), es una palabra performativa porque compromete por entero al sujeto que la profiere en una relación de sujeción con la otra parte. Al ser proferida, la protesta ubica a quien la pronuncia en la encrucijada de lo teológico con lo político. De este cruce de caminos salen otros dos: el de la teología política y el de su subversión, que calificaremos como lo teológico-político. ${ }^{2}$

\footnotetext{
${ }^{1}$ No sé si haya otra lengua que, como la nuestra, exhiba con toda intención su vena política en los diccionarios.

${ }^{2}$ Tomo esta distinción, aunque en un sentido diferente, de Lluís Duch (77 y ss.).
} 
Es necesario a esta altura preguntarnos qué entendemos por "teología”. Jacob Taubes la describe como: "Algo totalmente distinto de la descripción de un hecho terrenal (...) Lo sui generis de la teología no está en la red de las relaciones terrenales, es algo que esencialmente se encuentra afuera: lo absoluto" (Del culto 261). ${ }^{3}$ Por eso propone que sólo puede entenderse a sí misma ontológicamente, aunque por ser su objeto el Creador y que el sujeto se asume como criatura "la búsqueda no está finalmente orientada a la reflexión sino a la obediencia” (Del culto 262). Desde esta perspectiva, y en respuesta a una "dialéctica de la inversión", el iluminismo se entiende como ateo. "Históricamente, —dice Taubestanto la teología como el ateísmo proceden de la ortodoxia y del iluminismo". ¡Los dos, no "respectivamente”! El apareamiento entre la dogmática ortodoxa y la ilustrada engendrará a los gemelos teológico y ateo. La conjunción es clave: este pensador encontrará una coincidencia radical entre teología y ateísmo en el enunciado "Dios no existe", cuyo significado es "Dios no existe como objeto": ni es objeto de estudio para la ciencia ni tampoco es objeto de adoración, pues en ese caso degeneraría en mero ídolo (Taubes, Del culto 264). Este punto frágil en el cual se encuentran ateísmo (por la simple negación) y teología (tanto en su versión negativa como en la reflexión sobre la creatio ex nihilo) está registrado en la memoria literaria en el texto borgeano "De alguien a nadie" (la literatura, cuando es buena, tiene una vía directa exclusiva hacia las zonas oscuras de la comprensión; en otras palabras, el lenguaje de la ficción tiene una potencia de veracidad que supera a los saberes). En la exposición de Borges, el nombre plural de Dios (Elohim) se va contrayendo hasta la nada para, en ese silencio, poder designar - en potencia- el todo (Obras I 737). El camino a la teología negativa, por el cual "ser una cosa es inexorablemente no ser todas las otras cosas" le parece al sabio ciego una "falacia” que explica así: "la intuición confusa de esa verdad ha inducido a los hombres a imaginar que no ser es más que ser algo y que, de alguna manera, es ser todo". El autor lo ilustra con "las palabras de aquel rey legendario del Indostán, que renuncia al poder y sale a pedir limosna en las

\footnotetext{
${ }^{3}$ Aquí se explica la diferencia entre lo religioso (que es terrenal, óntico, ético...) y lo teológico. Por eso, sin la interpelación cristiana, el judaísmo, que siempre se entendió como una suma de preceptos por cumplir, no hubiese arribado a una teología (como lo hizo con Maimónides).
} 
calles: 'Desde ahora no tengo reino o mi reino es ilimitado, desde ahora no me pertenece mi cuerpo o me pertenece toda la tierra"'

Teología negativa exasperada... ¿cómo se traduce a su gemela política? En la República de Platón, Taubes encuentra que "la teología surgió como el planteo de un problema de teoría política" (Del culto 266). En efecto, la palabra aparece por primera vez en ese texto filosófico, eminentemente político, en el diálogo de Sócrates y Adimanto acerca de la poesía en el Estado. De allí (y por los desarrollos posteriores en la filosofía política) que este pensador contemporáneo afirme que "no hay teología sin implicaciones políticas ni política sin presupuestos teológicos" (Taubes, Del culto 267). Proudhon y Donoso Cortés, el revolucionario y el contrarrevolucionario, dice Taubes, coincidirán en que "en los fundamentos de la política siempre encontramos teología”. Pero hay que adentrarse en la prosapia: los términos políticos (revolución, oposición) tienen origen en la astronomía (Taubes, Del culto 270). Según el autor de Del culto a la cultura, la rebelión contra la jerarquía se gestó en el cambio de paradigma ptolemaico al copernicano, del "método medieval de la prueba por analogía al método experimental de la ciencia moderna", "el giro de una teología que presupone una analogía entre el reino de la naturaleza y el reino de la gracia, a una teología que establece una antítesis entre naturaleza y gracia". De la analogía medieval, según este autor, la teoría de la identidad "allanó el camino para la teología protestante de la interioridad". En este recorrido, como resultado de la especulación mística que "encuentra la vivencia de la identidad divina con el alma humana", secularizado, nace el concepto de autonomía (pensada como equilibrio), que abre el camino al ateísmo y se opondrá a la heteronomía (jerárquica) propia del teísmo. Como suele ocurrir, la oposición heteronomía/autonomía, según este agudo pensador, es gemela y pariente del par de opuestos sagrado/profano (en este último, el segundo término se define como exterior al primero: si lo sagrado es lo separado - ensimismado-, lo profano es aquello que se sitúa fuera, sin pasar el umbral del templo). En el pasaje hacia lo profano auspiciado por la Modernidad, en el plano político, la autonomía se relaciona con un equilibrio que, al romper la relación jerárquica de trascendencia, "debe resultar sólo de la relación inmanente de las fuerzas participantes" (Del culto 274). Nuestros tiempos modernos son herederos de 
Silvana Rabinovich

ese proceso de secularización que debe entenderse de manera multidisciplinar: con la astronomía, con la teología, con la antropología filosófica, con la epistemología, con la economía y con la política. (Entreveros de paradigmas teo-episemológicos de consecuencias éticas y eco-políticas catastróficas cuyas consecuencias se ven a la luz del día: de la diferencia a la analogía y luego a la identidad; de la Creación a la técnica, de un Dios separado a uno encarnado para finalmente engullirlo). Teofagia moderna.

Entre urdimbres y tramas interdisciplinarias, será posible abordar el entramado del progreso (inscrito en las coordenadas de lo profano y la autonomía) que Jacob Taubes acometió políticamente así: "La idea del progreso destruye el mito de la providencia". Y nos permitiremos traducirlo de esta manera: "la autonomía, en nombre del logos, en tanto razón adulta ilustrada, destruye a la heteronomía infantilizándola, esto es, privándola de palabra, de logos”. La Modernidad cabalgó sobre la oposición entre autonomía y heteronomía y lo sigue haciendo en nuestros días. ${ }^{4}$

Esta improbable dicotomía (a la que volveremos más tarde) se arraiga en un secularismo que ocultó la trama teológica de la política, tal como mostró el jurista Carl Schmitt en su Teología Política, “Todos los conceptos significativos de la moderna teoría del Estado son conceptos teológicos secularizados" (Teología Política I 37). Así, Dios se transformó en el "legislador todopoderoso", el milagro en el estado de excepción, etc. Ahora bien, el secularismo, en su búsqueda de la autarquía humana a través de la erradicación de la trascendencia - que reduce a jerarquía-, no hace más que aplastarla para aposentar al hombre en sus mismos espacios. Para conjurar el aplastamiento secularista, Schmitt busca volver a darle dignidad (legitimidad) a la jerarquía propia de la religión en el ámbito político representativo y por eso la orienta en su función coactiva en un sentido "cratológico" (Hartwich y Assmann en Taubes 2007c 151). Por otro lado, la subversión teológico-política que opera Taubes parte del mismo punto (reconocer los elementos religiosos de la política para rescatarla del aplastamiento al que fue sometida por la Ilustración en su pretensión autárquica) pero va en la dirección opuesta (propia de una “teología política negativa”), que cuestiona la legitimidad del orden

\footnotetext{
${ }^{4}$ Desarrollé el concepto de "heteronomía" en el Léxico de la vida social.
} 
político desde la comunidad. Jacob Taubes ve en Carl Schmitt a un "apocalíptico de la contrarrevolución", mientras que él orienta su propia apocalíptica hacia la revolución. Dice:

Carl Schmitt piensa en términos apocalípticos pero desde arriba, desde las potencias; yo pienso en términos apocalípticos pero desde abajo. Pero los dos tenemos en común la experiencia del tiempo y la historia como plazo, como plazo perentorio. Y ésta es en su origen una experiencia cristiana de la historia. (Teología política de Pablo 169)

Formado en la tradición talmúdica, pero lector también de la Biblia cristiana, y en especial de Pablo de Tarso, Taubes conoce íntimamente las sospechas de los rabinos respecto al poder imperial (ellos padecían el yugo de Roma y vislumbraban el tiempo mesiánico libre de dominación). Asimismo, las advertencias del profeta Samuel (I Samuel 8) acerca de los abusos de un rey sobre su pueblo, se leen entre esas líneas de distanciamiento irreconciliable con el jurista. Ahora bien, junto al primer punto de partida en común (la oposición al sueño secularista), hay otro más y concierne a la experiencia paulina del tiempo del fin: el katejon, que busca detener la anomia ante el fin del tiempo. Y desde este punto se distancian más aún: si, desde la teología política, Schmitt va a pensar la forma del Estado (fascista) capaz de suspender la ley para detener el caos, la teología política subversiva de Taubes, que discierne claramente la ilegitimidad en el poder instituido, desde una interpretación mesiánica fundada en la comunidad, promoverá la revolución. El par de opuestos contrarrevolución/revolución tiene su correlato en el par Estado/ comunidad.

\section{Sobre algunas protestas en México hoy (subversiones teológico-políticas de la teología política)}

Mi hipótesis es que, en México, hoy las protestas sociales, que tradicionalmente se entienden como netamente "políticas" - en el sentido ilustrado del término, esto es, ateas-, plantean una teología política contra-hegemónica que pone al descu- 
Silvana Rabinovich

bierto a la teología política del progreso que el oficialismo presenta como ilustrada ("científicamente probada", esto es, atea, pero que en realidad se funda en una ciencia obediente con las leyes del dios Mercado, cuya exégesis muchas veces se maquila en nuestras universidades).

Quisiera referirme al segundo par de opuestos planteados a propósito en la diferencia entre Taubes y Schmitt: Estado/comunidad con relación a la teología eco-política (hegemónica) y a su sub-versión comunitaria, esto es, contra-hegemónica.

La sentencia del Tribunal Permanente de los Pueblos (TPP) 2014 capítulo México registraba el 15 de noviembre de 2014:

[...] problemas socio-ambientales en 433 municipios de 21 entidades federativas del país, en los que habitan unos 40 millones de personas, esto es, una tercera parte de la población de México. México vive una crisis ambiental de enormes proporciones: el 70\% de los ríos del país están gravemente contaminados; en 30 años se ha triplicado el número de acuíferos sobreexplotados; el país ocupa uno de los primeros lugares en pérdida de diversidad biológica y bosques; más del $80 \%$ de los residuos industriales peligrosos no reciben tratamiento adecuado y solamente un $15 \%$ de los confinamientos de residuos urbanos cumplen parcialmente con la norma ambiental. Se constata pues una violación masiva y sistemática del derecho a un ambiente sano, consagrado en el Artículo 4 de la Constitución de México, desarrollado por la "Ley general del equilibrio ecológico y la protección al ambiente” de 1988. [...] Otro aspecto fundamental es la intensificación de un proceso general de despojo de las tierras, aguas, costas, minerales, recursos energéticos, territorios, espacio y servicios públicos e infraestructuras que el Estado mexicano aplica en beneficio de intereses corporativos mediante la aprobación de leyes que posibilitan la privatización del patrimonio de la Nación y de los pueblos. La reciente reforma energética es un ejemplo claro de esta tendencia.

En este ámbito es fundamental el papel y la responsabilidad de las empresas nacionales y transnacionales, en tanto habilitaron, exacerbaron, o facilitaron la devastación del medio ambiente y de los derechos humanos conexos con el mismo, obtuvieron enormes ganancias y trasladaron a las comunidades los costos ambientales de su accionar. 
En su Sentencia, el TPP, tras señalar el contexto histórico de impunidad, finca responsabilidades específicas en cuatro actores:

El Estado mexicano [en todos sus niveles]; las Empresas Transnacionales; Terceros Estados (como es el caso de los Estados Unidos de América o Canadá, entre otros) e Instituciones Internacionales (entre las que cabe mencionar a la OMC, el FMI, el Banco Mundial, la OMPI, ${ }^{5}$ entre otras).

Víctor Toledo, en su libro Ecocidio en México. La batalla final es por la vida, parafraseando a Leonardo Boff señala que minería, energía, agua, semillas no se reducen a un problema de contaminación o de extinción de especies: los conflictos ambientales en realidad son socio-ambientales. En este sentido, todo el discurso que tiende a culpabilizar a la población por el mal uso de aquello que dan en llamar "recursos", soslaya la responsabilidad de los cuatro actores señalados en la sentencia del TPP con relación a la devastación (socio) ambiental en sus diversas formas (y me permito agregar el prefijo "socio" a la devastación ambiental mencionada por dicha sentencia, porque hay una política clara que - por vías legales e ilegales, todas ellas ilegítimas - apunta a destruir la organización social en torno a la defensa de territorios atentando contra la vida de diversos luchadores sociales, entre quienes podemos contar también a numerosos comunicadores). ${ }^{6}$

De lo anteriormente expuesto, queda claro que la discusión urgente sobre el tema, inherente a la protesta en materia socio-ambiental, exige una reflexión sobre el discurso. Si nos diéramos a la tarea de empezar a registrar palabras clave que formen parte de un vocabulario teológico-político contra-hegemónico, podríamos empezar por proponer términos tales como: comunidad frente a Estado; bioculturalidad (Boege) frente a la dicotomía naturaleza/cultura, incluso en su versión multiculturalista; dignidad del territorio y sus derechos correspondientes, partiendo del derecho a lo sagrado, frente a los "recursos naturales" o "capital natural".

\footnotetext{
5 (Nota SR: Organización Mundial de la Propiedad Intelectual).

${ }^{6}$ Redacto este artículo iniciado en 2017, tras el asesinato del periodista Javier Valdéz (Culiacán, 15 de mayo de 2017) y de los hermanos activistas wixárikas Agustín y Miguel Vázquez Torres (Tuxpan de Bolaños, 20 de mayo de 2017). Basten estos nombres (los más recientes) para recordar a tantos otros.
} 
Silvana Rabinovich

Estas contra-posiciones, a diferencia de lo esperado, inician con la posición contra-hegemónica (señalada aquí en itálicas) por considerarla primera en el sentido tanto histórico cronológico como de prelación por defender la vida.

\section{Comunidad vs Estado}

Los lazos comunitarios son, por definición, horizontales: heterónomos hacia el interior (en el sentido en que la escucha del otro es prioritaria), buscan autonomía con relación al Estado. El caso de la comunidad de Cherán, Michoacán (Calveiro, Repensar) tal vez sea uno de los más claros, que al asumir la biocultura purépecha como forma de vida (en diálogo - que no en relación de subordinación- con el Estado nacional) decidió actualizar sus formas tradicionales de organización política separándose, es decir, expulsando de su territorio al Estado en todos sus niveles. Con esto logró no sólo erradicar las muertes violentas que asolaban el territorio, sino también detener la tala indiscriminada de los bosques sagrados. El Estado nacional se funda en relaciones centralizadas con individuos ciudadanos (muchas de ellas - incluso las cárceles - ahora se encuentran mediatizadas, "tercerizadas" por empresas privadas de servicios, cf. Calveiro, Violencias de Estado 246 y ss.) y en esta dirección, la comunidad (cuya trama es intersubjetiva y no individualista) representa un escollo porque las comunidades señalan su idolatría del progreso y del capital como profanación de la vida inseparable del territorio.

\section{Biocultura vs oposición "naturaleza/cultura”}

En nombre del progreso tecnológico y de la correspondiente cuantificación como demostración científica, el mega-extractivismo funda su misión pretendidamente redentora en la oposición heredada entre naturaleza y cultura. Teología política hegemónica disfrazada de atea: el discurso tecnólatra, como se puede apreciar 
tanto en su versión neoliberal como "populista", se halla plagado de figuras teológicas secularizadas. ${ }^{7}$ A ella se llega por la ruptura epistemológica que Taubes atribuía al cambio de paradigma copernicano, en el cual la providencia queda aplastada por el progreso legitimado por el historicismo positivista. Reiteradamente, los ciudadanos que "protestaron" guardar la constitución por el bien de la Unión... al modo de los inquisidores, imponen su fe sobre formas bioculturales ancestrales. Éstas basan su protesta (contra-hegemónica) en una concepción biocultural, que se entiende como el conocimiento ecológico, las tecnologías, saberes, experiencias que provienen de la interacción de los pueblos con los diversos ambientes o paisajes naturales (Boege 16). La biocultura como concepción de vida (comunitaria), muestra el absurdo de separar naturaleza de cultura (individualista).

\section{Dignidad del territorio (derecho a lo sagrado) vs "recursos o capital natural"}

Aquí es donde más claramente la teología política del progreso (que en su miopía ve a la naturaleza como valor de cambio) es subvertida por el derecho a lo sagrado. Nos extenderemos en esta última contra-posición. La sentencia del TPP cita parte del Dictamen sobre Devastación Ambiental y Derechos de los Pueblos (Ciudad de México, 15 y 17 de noviembre de 2013):

[...] la expansión de la cosmovisión mercantil en su forma neoliberal no tiene precedentes y está totalmente fuera de control. Esta cosmovisión no percibe los árboles, ríos, tierra, montañas como seres con su propia dignidad y derechos, sino como parte de un mundo de "recursos naturales" y "capital natural", o sea, bienes y servicios que esperan el desarrollo de la inversión para poder ser consumidos productivamente tras ser intercambiados en un mercado. Este proceso tiene como fin una acumulación sin comparación en la historia humana, y su

\footnotetext{
${ }^{7}$ Cf. El número 24 de la revista Tabula Rasa está dedicado a la teología de los extractivismos. Para muestra, un botón: en una de sus numerosas frases célebres, el ex presidente Vicente Fox dijo que "Pemex es igual a la Virgen de Guadalupe, son símbolos para los mexicanos que deben manejarse con mucho cuidado" (Méndez).
} 
Silvana Rabinovich

resultado devastador ha sido la decadencia casi total del planeta y de sus tierras, mares, ríos, lagos, bosques, praderas, cuencas y otros lugares, lo mismo que de las comunidades originarias que los habitan, y de sus formas de pensar, vivir e intercambiar con el universo.

El 19 de abril de 2012 en el Senado de la República tuvo lugar el "Foro de análisis Wirikuta, el derecho a lo sagrado". En su pronunciamiento, las autoridades tradicionales, civiles y agrarias del pueblo wixárika, en nombre de todas las hermanas y hermanos, entre otras cosas, dieron una lección de biocultura:

El territorio, desde la concepción indígena, constituye el espacio natural de vida, concebido como una unidad ecológica fundamental donde se desarrolla la vida en sus múltiples expresiones y formas; este espacio natural es fuente de saberes y conocimientos, de cultura, identidad, tradiciones y derechos. Así, el territorio, integra los elementos de la vida en toda su diversidad natural y espiritual: la tierra con su diversidad de suelos, ecosistemas y bosques, la diversidad de los animales y las plantas, los ríos, lagunas y esteros. Los ecosistemas naturales son considerados, por los pueblos indígenas como hábitat de los dioses protectores de la diversidad de la vida y gracias a ellos, se mantiene la integridad y el equilibrio del bosque, de los ríos, de las lagunas y la fertilidad del suelo, lo que permite que las plantas y animales puedan vivir y reproducirse.

La reivindicación de nuestros derechos humanos y como pueblos indígenas que estamos haciendo de manera pacífica, desde un consenso en nuestras asambleas comunitarias, nuestro órgano máximo de toma de decisiones, dentro del marco constitucional, respaldados por la misma constitución, los tratados y convenios internacionales que ya tienen jerarquía constitucional sobre leyes generales y secundarias; la hacemos decididos de que no debe haber nunca más un México sin nosotros, nunca más un México donde no se respeten nuestros derechos.

Apelando a la "protesta" del C. Presidente, además de exigir, entre otros puntos, la cancelación de las concesiones mineras en Wirikuta y su zona de influencia por violar los "derechos culturales y colectivos", en el punto seis proponen que "se reconozca fehacientemente en el marco jurídico mexicano" los puntos que citamos a continuación: 
Protestar en México

- La personalidad de los pueblos indígenas como sujetos de derecho público y no como entidades de interés público, con plenos derechos constitucionales y políticos.

- Implementar mecanismos para el pleno acceso a la jurisdicción del estado que faciliten la demanda de los derechos individuales y colectivos que afectan a los pueblos ante las instancias judiciales correspondientes.

- El reconocimiento al derecho territorial de los pueblos entendidos estos como el espacio donde se desarrolla toda la cultura.

- Implementación de mecanismos para las consultas a los pueblos para la aprobación de las políticas públicas y acciones que afectan directa o indirectamente la vida de los pueblos bajo el fundamento de la declaración de las naciones unidas sobre el derecho de los pueblos indígenas y su incorporación a la legislación nacional.

¿Qué responden ante esta protesta (en los dos sentidos del término) los que protestaron guardar la Constitución? Poco... ${ }^{8}$ El 27 de mayo de 2017, a una semana del asesinato de los líderes sociales wixárikas Agustín y Miguel Vázquez Torres (defensores de la tierra), las autoridades indígenas anunciaron que ya identificaron a los cinco autores materiales del doble asesinato y que dan plazo hasta el 9 de junio para que las autoridades del Estado capturen a los autores intelectuales, "cuando en la comunidad de Ocota de la Sierra (norte de Jalisco) se reúnan en asamblea las autoridades indígenas para tomar decisiones respecto a la forma de organizarse para proteger a su gente y a su territorio" (La Jornada).

Para concluir estas primeras reflexiones hacia un vocabulario teológico-político contra-hegemónico: México tiene una lengua oficial, pero sus lenguas nacionales son muchas (68 familias lingüísticas, 364 "variantes lingüísticas", en términos y cifras oficiales del Instituto Nacional de Lenguas Indígenas). Es un Estado responsable por muchas comunidades indígenas y otras mestizas, unas rurales y otras urbanas que, no sin dificultad, se van tejiendo. La protesta a favor de la defensa de

${ }^{8}$ En octubre de 2012 la CNDH emitió una recomendación (56/2012) donde reconoce las violaciones de autoridades federales, estatales y municipales a derechos humanos fundamentales del pueblo wixárika, Wirikuta debe entenderse como expresión de la cosmovisión del pueblo wixárika y sus tradiciones así como el derecho constitucional a la consulta (Frente en Defensa de Wirikuta). 
Silvana Rabinovich

la tierra, en México se expresa en la lengua oficial, que se asume como traductora de las múltiples lenguas mexicanas. Estas expresiones traductoras surgen como contra-posiciones que dejan oír la potencia de lo teológico-político que anida en la traducción. La protesta es palabra performativa que, como bisagra entre lo teológico y lo político, en su versión contra-hegemónica (comunitaria), cuando sale a la calle o llega a los enclaves de la hegemonía (estatal), puede hacerla retemblar.

\section{Silvana Rabinovich (silvanar@unam.mx)}

Doctora en Filosofía, Facultad de Filosofía y Letras de la Universidad Nacional Autónoma de México. Maestra en Filosofía, Universidad Hebrea de Jerusalén. Licenciada en Filosofía, Universidad Nacional de Rosario, Argentina. Investigadora definitiva de tiempo completo, Instituto de Investigaciones Filológicas, UnAM. Tutora del Posgrado en Filosofía, FFyL, UnAM. Miembro del SNi Nivel II. Responsable del proyecto PAPIIT IN 402317 "Heteronomías de la justicia: nomadismo y hospitalidad en el lenguaje", IIFL, UNAM.

Los libros publicados de su autoría son: La Biblia y el drone. Sobre usos y abusos de figuras bíblicas, IEPALA, Madrid, 2013. Heteronomías de la lectura (ed. libro electrónico), Destiempos, México DF, 2013. La huella en el palimpsesto. Lecturas de Levinas, UACM, México DF, 2005. Es editora de Retornos del Discurso del "Indio" (para Mahmud Darwish). unAm-IIfL-Apofis, CDMX, 2017. Autora de artículos y capítulos de libro publicados en México, Argentina, España, Francia, Brasil, Bélgica y Estados Unidos. Traductora del hebreo de Martin Buber y del francés de Emmanuel Levinas, Enzo Traverso y Hélène Cixous. En prensa: Interpretaciones de la heteronomía, IIFL, UNAM.

\section{Obras Citadas}

Boege, Eckart. El patrimonio biocultural de los pueblos indígenas de México Hacia la conservación in situ de la biodiversidad y agrodiversidad en los territorios indí- 
genas. México: INAH, Comisión Nacional para el Desarrollo de los Pueblos Indígenas, 2008.

Borges, Jorge Luis. "De alguien a nadie". Otras Inquisiciones. en Obras completas I. Buenos Aires: Emecé, 1974: 737-739.

Calveiro, Pilar. Violencias de Estado. La guerra antiterrorista y la guerra contra el crimen como medios de control global. Buenos Aires: Siglo XXI, 2012.

Calveiro, Pilar. "Repensar y ampliar la democracia. El caso del Municipio Autónomo de Cherán K’eri”. Argumentos 27.75 (2014):193-212. Buenos Aires, Argentina. $<$ http://www.redalyc.org/articulo.oa?id=59533233009>

Duch, Lluís. Religión y política. Barcelona: Fragmenta Editorial, 2014.

Méndez, Enrique. "Vicente Fox compara Pemex con Virgen de Guadalupe". La jornada. 11 de marzo de 2000. Web. 24 de mayo de 2017. <http://www.jornada. unam.mx/2000/03/11/promovera.html.>

Foro de análisis para una propuesta legislativa. "Wirikuta, el derecho a lo sagrado". Web. 29 de mayo de 2017. <http://www.frenteendefensadewirikuta.or$\mathrm{g} / \mathrm{?} \mathrm{p}=2732>$

Frente en Defensa de Wirikuta Tamatsima Wahaa. "Wirikuta el FDW se congratula por recomendación de la CNDH". Salvemos Wirikuta. 8 de octubre de 2012.Web. 24 de mayo de 2017. <http://salvemoswirikuta.blogspot.mx/2012/10/wirikuta-el-fdw-se-congratula-por.html.>

Hartwich Wolf-Daniel, Assmann Aleida y Jan. "Epílogo”.. Jacob Taubes, La teología política de Pablo. Madrid: Editorial Trotta, 2007.

Instituto Nacional de Lenguas Indígenas. "Catálogo de las lenguas indígenas nacionales: variantes lingüísticas de México con sus autodenominaciones y referencias geoestadísticas". Diario Oficial 2008. Web. 20 de mayo de 2017.<http://www. inali.gob.mx/pdf/CLIN_completo.pdf >

G. Partida, Juan Carlos. "Resistencia Wixárika. Narcos asesinaron a los hermanos Vázquez Torres". La Jornada. 27 de mayo de 2017. Web. 29 de mayo de 2017. $<$ http://www.jornada.unam.mx/2017/05/27/politica/o02n1pol> 
Manrique Velasco, Carlos. "El nuevo modelo constitucional de toma de protesta del Ejecutivo Federal ¿maximiza la democracia?”. Hechos y derechos 10 (2012). Web. 20 de mayo de 2017. <https://revistas.juridicas.unam.mx/index.php/hechos-y-derechos/article/view/6721/8657>

Rabinovich, Silvana. "Heteronomía". Léxico de la Vida Social, Fernando Castañeda, Laura Baca, Alma Imelda Iglesias. México: UNAM FCPys-SITESA, 2016: 332-336.

Schmitt, Carl. Teología política. Madrid: Trotta, 2009.

Tabula Rasa 24 (2016): 1-424. Universidad Colegio Mayor de Cundinamarca, Bogotá, Colombia. <http://www.revistatabularasa.org/numero-24>

Taubes, Jacob. Del culto a la cultura. Elementos para una crítica de la razón histórica. Trad. Silvia Villegas. Buenos Aires: Katz Editores, 2007.

Taubes, Jacob. La teología política de Pablo. Madrid: Editorial Trotta, 2007.

Toledo, Víctor. Ecocidio en México. La batalla final es por la vida. Ciudad de México: Grijalbo, 2015.

Tribunal Permanente de los Pueblos. "Libre comercio, violencia, impunidad y derechos de los pueblos de México (2011-2014)”. Sentencia de la Audiencia Final, llevada a cabo entre el 12 y el 15 de noviembre de 2014. Web. 29 de mayo de 2017. <http://redtdt.org.mx/wp-content/uploads/2014/11/TPP-M\%C3\%89XICOSENTENCIA-FINAL.pdf 